\title{
A INFLUÊNCIA DA TUTORIA NA PRÁTICA DA EDUCAÇÃO A DISTÂNCIA
}

Cristina Oliveira Maia | mariacristina1@gmail.com

Doutorado em Ciência pela UFRJ. Professora do Mestrado Profissional do Instituto de Bioquímica Médica da UFRJ e coordenadora da área de Cognição da Diretoria de Extensão da Fundação CECIERJ.

Denise Rocha Corrêa Lannes | lannesdenise@gmail.com

Doutorado em Educação, Gestão e Difusão em Biociências pela UFRJ. Professora adjunta do Instituto de Bioquímica Médica e coordenadora da Especialização em Ensino de Ciências e do Mestrado Profissional da UFRJ. Professora colaboradora da área de Prática Docente da Diretoria de Extensão da Fundação CECIERJ.

\section{Resumo}

Neste artigo analisamos as relações e resultados obtidos por cursistas de disciplinas de um curso de formação continuada para professores da Educação Básica na modalidade educação a distância. Nosso trabalho se desenvolve ao longo de vários períodos do referido curso. A análise da estrutura das disciplinas, o perfil dos tutores e dos cursistas dão um panorama das características desse grupo. Esperamos poder contribuir para a elucidação de alguns pontos na discussão sobre as características relevantes de tutores em EaD. Os tutores observados, em sua maioria, não apresentavam todas as características que tomamos como relevantes para tutores em $\mathrm{EaD}$, ou seja, ser especialista na área em que atua, estar atuando com pesquisa na academia e ter experiência prévia em EaD. Os tutores especialistas em suas áreas, com experiência em EaD e com atividade acadêmica constante, mesmo atendendo um número em alguns casos quatro vezes maior que seus colegas que não apresentaram essa característica, apresentaram turmas com evasão significativamente menor e sem reprovação para esse grupo.

\section{Palavras-chave}

Formação Continuada. Educação a Distância. Tutoria a distância. 


\section{The Influence of Mentoring in the practice of Distance Education}

\section{Abstract}

In this article we analyze the relations and the results gotten from students of long-distance disciplines from a formation course to basic education teachers in the modality of long-distance education. Our work develops through many periods of said course. The analysis of the disciplines structure, the tutors and students profile give us a view of the characteristics in these two groups. We hope to contribute to the elucidation of some points in the discussion about the relevant characteristics of tutors in long-distance education. Most observed tutors don't show all the characteristics which we deem as relevant for tutors on long-distance education, such as being a specialist in their area, doing research on the academy and having previous experience on long-distance education. The specialist tutors on their areas, with experience on long-distance education and with constant academic activity, in some cases even making a number four times bigger than their colleagues which don't show this characteristic, presented classes with an evasion significantly smaller and any students who failed, for that group.

\section{Keyword}

Professional Continuing Education. Distance Education. Distance tutorship.

\section{Introdução}

A sociedade reconhece a educação como um bem necessário ao desenvolvimento $e$ um direito de todos, sem discriminação de gênero, idade, etnia ou padrão cultural (BARBOSA; REZENDE, 2006), e a educação a distância $(\mathrm{EaD})$ amplia as possibilidades de promoção dessa educação, permitindo a permanência do indivíduo que deseja estudar em seu ambiente profissional, cultural e/ou familiar (GALERA, 1998). A EaD reduz, ainda, as barreiras de acesso à formação, ao eliminar ou diminuir os obstáculos como os geográficos, de tempo e de idade; atender a um grande número de alunos a um só tempo $e$ a um custo potencialmente reduzido, embora exija investimento financeiro inicial (RUMBLE; OLIVEIRA, 1992; COGAN, 1995; LISONI; LOYOLLA, 2012).

A EaD também flexibiliza o aprendizado, oferecendo a possibilidade de autonomia, sem rigidez quanto aos requisitos de espaço, apresentando potencial mediador e integrador, por estabelecer uma interação dialógica, no mínimo, bidirecional (two-way communication) (GARRISON et.al., 1999), que permite comunicação do professor/tutor para os estudantes e dos estudantes para o professor/tutor, chamada por Rafaeli e Sudweeks (1997) de comunicação reativa, em que um lado responde ao outro, mediatizada pelo uso de tecnologias que deverão estar adequadas a esse objetivo.

Esta é, então, uma modalidade de ensino que demonstra grande potencial de eficácia, não só pelo desenvolvimento de tecnologia, cada vez mais acessível, como também pela amplitude de ação e pela demanda que apresenta. Segundo dados do Censo da Educação Superior (MEC/Inep, 2011) o número de matrículas, somente nos cursos de graduação em $\mathrm{EaD}$, cresceu mais de $100 \%$ entre 2007 e 2009 (Figura 1). 


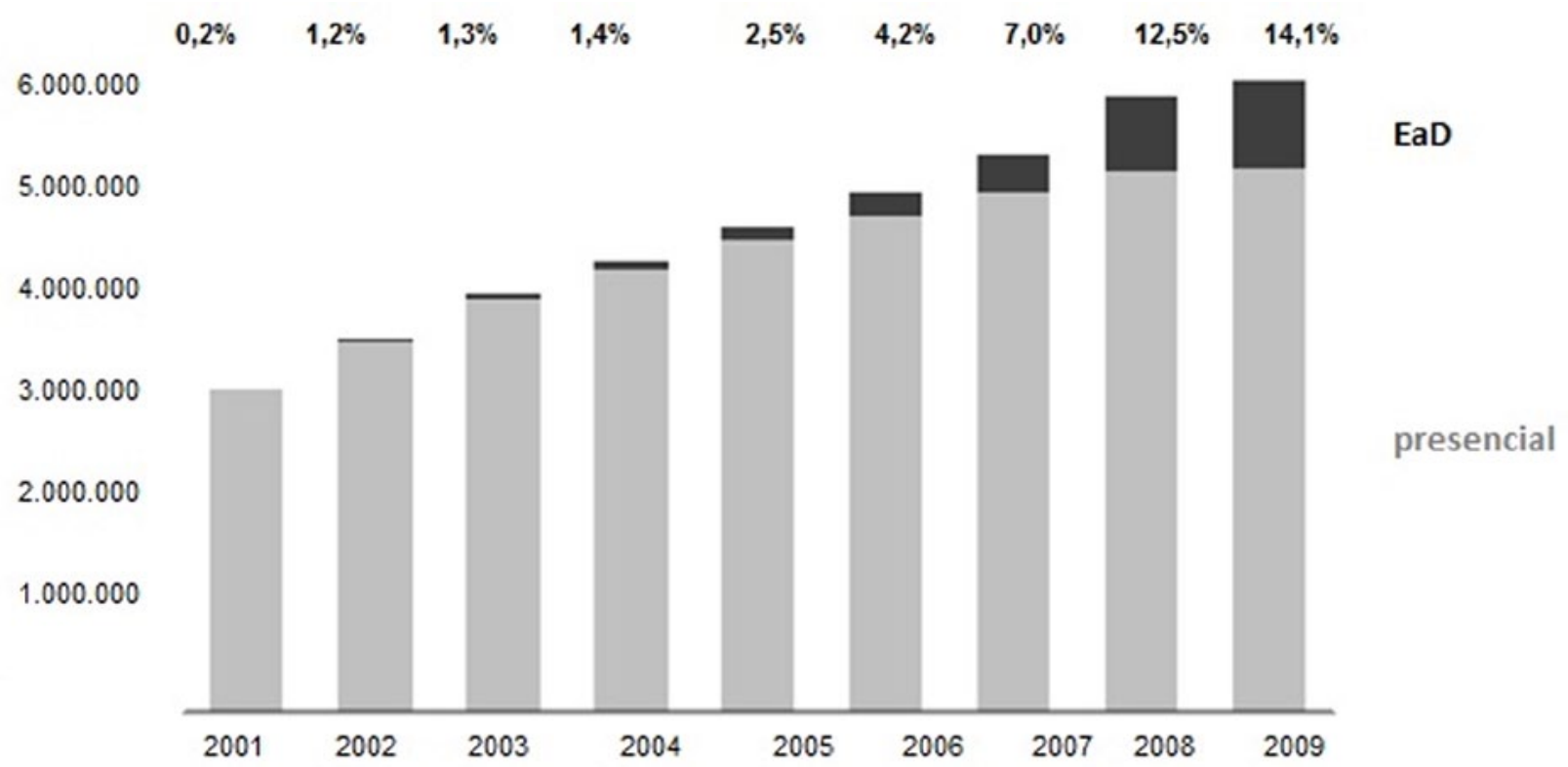

Figura 1: Evolução do número de matrículas na graduação por modalidade de ensino - Brasil, 2001-2009.

Fonte: Censo da Educação Superior/MEC/Inep, 2011.

Neste artigo analisamos o perfil e as relações entre tutores e cursistas de disciplinas a distância, verificando sua permanência e o resultado final nas disciplinas, em uma abordagem mais quantitativa que qualitativa, que, porém, permitiu reflexões importantes. As disciplinas escolhidas integram cursos livres na modalidade a distância com carga horária de 30 horas para professores da Educação Básica em formação continuada.

São disciplinas que buscam um estilo de pedagogia sustentado pela modalidade comunicacional bidirecional, que supõe participação, cooperação e multiplicidade de conexões entre informações $e$ atores envolvidos, cursistas e tutores. Seria uma abordagem pedagógica como a descrita por Valente (2002), "estar junto virtual”, ou por Harasim et al (1995), learning network.

Nesse tipo de abordagem, o tutor é um elemento indispensável na rede de comunicação que vincula os cursistas à instituição de ensino. $\mathrm{O}$ papel do tutor é de parceria, constituindo-se em estímulo para a aprendizagem e incentivo à reflexão, pois, além de manter a motivação dos alunos, possibilita a retroalimentação acadêmica e pedagógica do processo educativo.
Entretanto, não podemos deixar de considerar que a prática dos tutores é uma interseção de diferentes contextos e é regida também por regulações pessoais e organizacionais (NÓVOA, 1999, apud BARBOSA; REZENDE, 2006), fatos que influenciam não só na autonomia, mas também no estilo de interação dialógica desses profissionais.

\section{Perfil dos cursistas}

Os indivíduos incluídos na pesquisa realizaram suas inscrições entre 2005 e 2007 para a área de Biologia, num total de 14 edições de disciplinas identificadas aqui por suas iniciais, BMEM e NC, e em dois períodos distribuídos nos anos de 2009 e 2010, para a área de Educação em Ciências, em duas edições da disciplina CP. Nas figuras as disciplinas estão identificadas pelo período em que foram oferecidas: 2005-3, 2006-1, 2006-2, 2006-3, 2007-2, 2009-2 e 2010-2, podendo ocorrer mais de uma no mesmo período.

Numa análise cuidadosa decidimos organizar a amostra em dois grupos, uma vez que as áreas das disciplinas eram diferenciadas, porém ambas oferecidas pela mesma instituição e coordenadas pela mes- 
ma equipe. Além disso, as disciplinas oferecidas são estruturalmente diferenciadas, segundo o conceito de Moore, "[a estrutura] descreve o grau em que um programa de educação pode acomodar ou responder às necessidades individuais de cada aluno" ${ }^{1}$ (MOORE, 1993) Ou seja, a estrutura seria a medida da resposta de um programa às necessidades individuais do aluno.

Nesse sentido, as duas primeiras disciplinas, oferecidas entre 2005 e 2007 (BMEM e NC), poderiam ser consideradas previamente estruturadas, contendo questões conceituais objetivas que deveriam ser respondidas e seriam posteriormente comentadas pelos tutores que aguardavam as tréplicas, não obrigatórias, dos cursistas, enquanto a última $(\mathrm{CP})$, oferecida em duas versões nos anos de 2009 e 2010, iniciava-se desestruturada e ia sendo construída ao longo do período junto aos cursistas, com atividades entremeadas a fóruns de discussão conceituais e fóruns de discussão livre, também sem a obrigatoriedade de retorno nas respostas, sendo por isto considerada semiestruturada.

A maior parte dos professores cursistas declarou em cadastro individual possuir computador pessoal (PC) com banda larga em casa e fazer uso dele com mais frequência para "edição de textos e planilhas, correio eletrônico, pesquisas na internet e outros", demonstrando facilidade no manuseio e no acesso à internet.

Outras características declaradas no mesmo cadastro:

Tabela 1: Características dos professores inscritos, segundo dados colhidos em ficha cadastral - Fundação Cecierj, Diretoria de Extensão, 2011

\begin{tabular}{c|c|c|c}
\hline \multirow{2}{*}{ PERÍODOS } & & $\mathbf{2 0 0 5 - 2 0 0 7}$ & $\mathbf{2 0 0 9 - 2 0 1 0}$ \\
\hline \multirow{4}{*}{ ATUA EM } & TOTAIS & $\mathbf{2 . 6 6 5}$ & $\mathbf{2 7 0}$ \\
\cline { 2 - 4 } & & \multicolumn{2}{|c}{ \% de cursistas } \\
\cline { 2 - 4 } & sem escola & 36,0 & 44,8 \\
\hline \multirow{2}{*}{ FORMAÇÃO } & Escola pública & 45,0 & 41,1 \\
\cline { 2 - 4 } & Licenciatura & 86,0 & 74,8 \\
\hline \multirow{2}{*}{ ÁREA DE } \\
FORMAÇÃO & Bacharelado & 10,0 & 13,3 \\
\cline { 2 - 4 } & C. Humanas & 8,0 & 63,7 \\
\hline
\end{tabular}

Como observamos na Tabela 1, a maioria dos candidatos atua em escolas públicas e optou pelo curso de Licenciatura Plena durante o período de graduação. Esse é o público para o qual esses cursos estão direcionados preferencialmente, segundo edital de convocação.

A porcentagem de cursistas oriundos da área de Ciências Humanas e Sociais cresceu, percentualmente, cerca de oito vezes, passando de $8 \%$ entre 2005

1 Do original: "[structure] describes the extent to which an education programme can accommodate or be responsive to each learner's individual needs". e 2007 para 63,7\% nos anos de 2009 e 2010, uma vez que mudou também o foco da área das disciplinas oferecidas pela equipe (Tabela 1 ).

Percebemos também pequeno aumento na porcentagem de profissionais que se declaram inativos, ou seja, que não estão atuando em sala de aula, passando de um total de 36\% entre 2005 e 2007 para 44,8\% em 2009 e 2010. Podem estar incluídos nesses grupos os alunos de períodos finais de licenciaturas, que têm permissão para participar dos cursos, assim como profissionais que ainda não se colocaram no mercado ou que deixaram recentemente suas escolas por variados motivos. 
A média de idade para estes cursos foi analisada somente nos anos de 2009 e 2010, já que essa característica não havia sido preenchida pela maior parte dos candidatos nas fichas de cadastro anteriores a esse período. A maioria dos candidatos encontra-se na faixa de 29 a 38 anos, concordando com a informação obtida na literatura. Segundo o Relatório analítico da aprendizagem a distância no Brasil, "a faixa etária mais presente é a que vai de 30 a 34 anos, que predomina em $28 \%$ das instituições, responsáveis por $35 \%$ dos alunos" (Censo EAD.BR, 2010, p. 8).

Uma vez obtidos esses dados, questionamos se o tempo de carreira ou a idade influenciariam a pro- cura por esse tipo de curso. Verificamos na literatura a existência de categorias de acordo com a fase da carreira vivida pelo indivíduo. Um estudo realizado pela socióloga Lüdke (1996) com professores em diferentes fases na carreira deu origem a categorias de acordo com o tempo de magistério. Estas foram adaptadas de uma pesquisa do professor Huberman, da Universidade de Genebra, na Suíça, para a realidade brasileira no que diz respeito ao tempo de carreira, já que no Brasil o encerramento da atividade profissional acontece antes do previsto por Huberman (1992) ${ }^{2}$. Tanto Huberman quanto Lüdke afirmam tratar-se de um estudo flexível $e$, portanto, sujeito a diferentes influências, sejam isoladas ou combinadas.

Quadro 1: Ciclo de vida profissional docente proposto por Lüdke (1996)

\begin{tabular}{|c|c|}
\hline $\begin{array}{c}\text { Tempo de magistério } \\
\text { (anos) }\end{array}$ & Fases da carreira (Lüdke) \\
\hline $01-06$ & Inicial \\
$07-12$ & Estabilização \\
$13-24$ & Diversificação \\
25 ou mais & Desinvestimento \\
\hline
\end{tabular}

Adaptando essas categorias à amostra de cursistas das edições da disciplina oferecida em 2009 e 2010 e comparando com a média de idade dos mesmos, encontramos os resultados expressos na Figura 2.

2 No Brasil, em regra geral, para os servidores públicos, a aposentadoria passa a ser possível quando se atinge uma idade mínima e de tempo de contribuição: o homem aos 60 anos de idade e 35 anos de tempo de contribuição e a mulher com 55 anos de idade e 30 anos de contribuição. No caso dos professores, o docente que comprove tempo exclusivamente prestado em funções do magistério da Educação Infantil, Ensino Fundamental e Ensino Médio, há a redução de cinco anos na idade e no tempo de contribuição; nesse caso, os professores passam a se aposentar com 55 anos de idade e 30 anos de contribuição e as professoras com 50 anos de idade e 25 anos de contribuição (BRASIL, Previdência Social. Disponível em: http://www.previdencia.gov.br/conteudoDinamico.php?id=19/). 

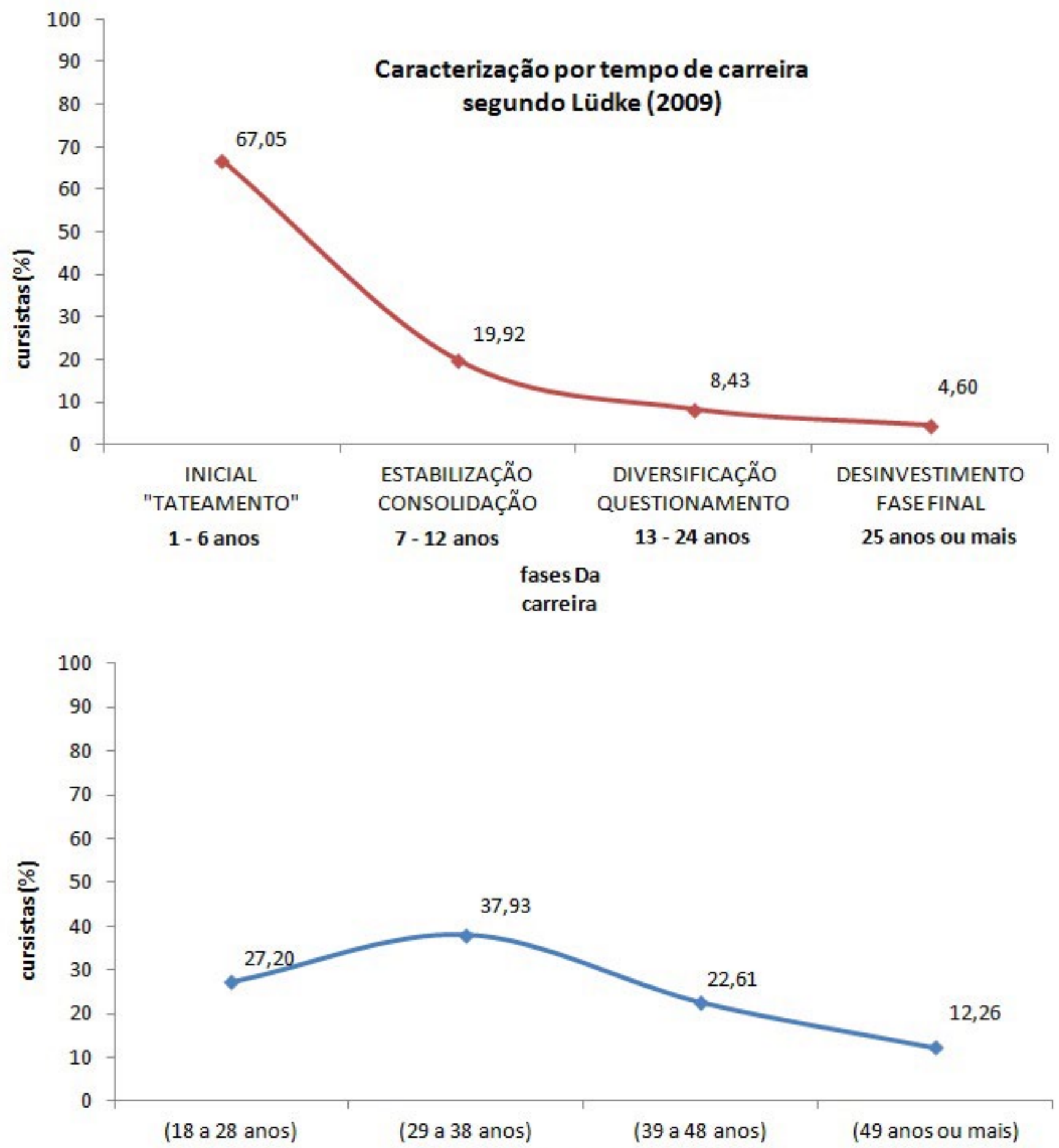

Grupos de idades

Figura 2: Curva de distribuição de 261 cursistas por tempo de carreira (a) e idade (b), permitindo a comparação do com as fases observadas por Lüdke (2009).

Fonte: Gerência de alunos da Fundação Cecierj, consulta realizada em $2011^{3}$.

3 Dados obtidos em: http://gerencia.cecierj.edu.br (protegido por senha). 
Como já havíamos identificado, o maior grupo (37,9\%) apresenta idades entre 29 e 38 anos (Figura $2 \mathrm{~b}$ ) enquanto mais de $65 \%$ da nossa amostra estão na fase inicial ou de "tateamento" (Figura 2a), que, segundo Huberman (1992, p. 39), é marcada por descobertas e sobrevivência. É quando o professor começa a tentar pôr em prática a teoria vista ao longo de sua formação e quando descobre que precisa adaptar esta teoria à prática da docência. É um resultado que difere daquele encontrado por Huberman (1992), que afirma uma tendência maior de procura por cursos de formação continuada em grupo de professores entre treze e vinte e quatro anos de carreira, denominada por ele "fase de diversificação/questionamento".

Relacionamos as duas informações para esse grupo de professores e encontramos o perfil apresentado na Figura 3.

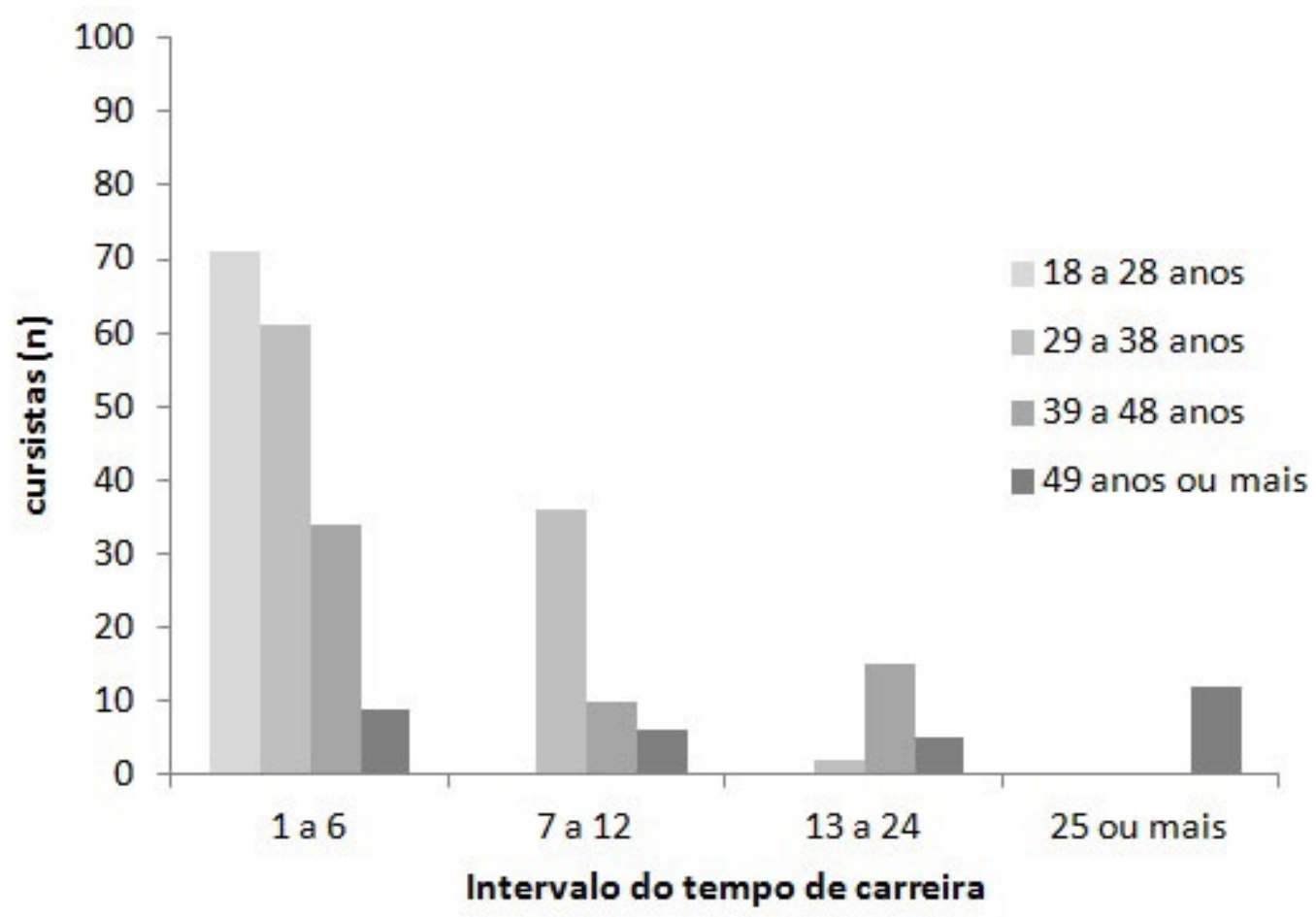

Figura 3: Caracterização dos cursistas por idade em grupos segundo tempo de carreira $(n=261)$.

Fonte: Gerência de alunos da Fundação Cecierj, consulta realizada em 2011.

Observamos que os indivíduos entre 18 e 48 anos de idade estão, em sua maioria, no grupo de recém-ingressados no magistério (Figura 3). Estando nossa amostra, em sua maior parte, em fase inicial de carreira, podemos supor que esses indivíduos busquem, nesses cursos de atualização e formação continuada, elementos que auxiliem de alguma forma a realização da práxis pedagógica.

É importante notar que, nesse grupo, 67\% dos participantes estão em fase inicial de carreira e que a faixa etária é bastante extensa (Figura 2a). Outros autores também consideram as fases descritas por Huberman segundo a idade do profissional (BURKE et al., 1987; CAVACO, 1991 e 1993; HUBERMAN e SCHAPIRA, 1985). As faixas etárias estariam associadas ao tempo de magistério; assim, quanto mais velho, mais tempo exercendo a profissão. Em nossa amostra encontramos uma maioria de profissionais em faixa etária maior que o descrito pelos autores citados como iniciantes na profissão. Muitos terminaram sua formação tardiamente e alguns mudaram de profissão ou ingressaram nela tardiamente. 
Certamente, segundo próprio Huberman,

A distinção de fases no desenvolvimento profissional não implica uma perspectiva de causalidade ou que todos os professores tenham que passar pelas mesmas fases nos mesmos momentos, pois múltiplos fatores influenciam o desenvolvimento profissional do professor (HUBERMAN, 1992, p. 55).

Portanto, temos um público com faixa etária mais ampla, bastante envolvido com a formação continuada e buscando novos argumentos na profissão.

\section{Desenvolvimento da pesquisa}

\section{a) Fatores relacionados ao abandono ou de- sistência em EaD}

Os cursos livres, procurados por profissionais na ativa, que oferecem pouco retorno com relação à progressão profissional e/ou titularidade e que podem ser interrompidos a qualquer momento, não inviabilizando o retorno do aluno ao mesmo curso numa próxima edição, num próximo semestre, apresentam historicamente elevadas taxas de evasão em EaD (ALMEIDA, 2008, 2010; ALMEIDA; ILDETE, 2008). O próprio Censo EAD.BR (2010, p. 9) afirma que "o nível educacional que mostra maior evasão é o que tem cursos de menor duração, os de extensão."

Além disso, segundo o mesmo Censo,

\begin{abstract}
O número de alunos por profissional também parece estar pouco relacionado com o índice de evasão. O número de alunos por profissional docente está abaixo da média nas instituições com os três maiores índices de evasão. Já no que se refere aos profissionais de apoio, as instituições com os menores índices de evasão (até 15\%) têm um número pouco menor de alunos por profissional (Censo EAD.BR, 2010, p. 9).
\end{abstract}

Segundo Biazus (2004), evasão definitiva seria a "saída terminante" do curso, ou seja, o cursista se afasta da instituição por "abandono, desistência definitiva do curso ou transferência para outra instituição".
Para fins de diferenciação nos eventos, determinamos "abandono" a retirada voluntária do cursista antes do início das atividades. Já "desistência" seria a retirada voluntária do cursista a qualquer momento após o início das atividades, porém antes de realizar as atividades de avaliação final.

Vários fatores já foram relacionados ao sucesso ou não de alunos que optam pela modalidade EaD. No Censo EAD.BR (2010, p. 9) encontramos os motivos "financeiro" e "ausência de tempo" como os mais citados de maneira ampla, mas, ao especificar o público de evadidos, percebe-se que cursistas não habituados a esses tipos de cursos apresentam "desconhecimento do método ou seu estranhamento que não são desprezíveis, sendo citados por um terço das instituições (que participaram do censo)", nos termos do relatório. Os recursos tutoriais e a eficiência na comunicação, no diálogo e no esclarecimento aos cursistas seriam, então, fatores determinantes na manutenção de alguns deles.

Buscando dados mundiais, encontramos resultados semelhantes àqueles publicados no Brasil. Em publicação sobre o tema, Moore e Kearsley (2007) admitem que os índices de evasão venham diminuindo, assim como visto no Censo EAD.BR (2010). Em trabalho publicado em 2002, Tresman identificou um percentual pouco maior de evasão na Universidade Aberta da Grã-Bretanha para alunos que não possuíam nenhuma experiência anterior nessa modalidade de ensino.

Para Moore e Kearsley (2007), existe uma grande dificuldade metodológica na identificação das causas da evasão, porque ela em geral é multifatorial. A falta de tempo, como visto anteriormente, é o fator mais citado (OSTMAN; WAGNER, 1987; NASH, 2005) e pode estar associado à idade mais avançada dos estudantes de $\mathrm{EaD}$, que, além de estudar, possuem os compromissos da vida adulta.

Garcia Aretio (1994) concorda que os fatores que levam à evasão podem estar associados a elementos diversos: a estrutura e a organização do curso, o material oferecido, a comunicação entre os elementos do programa de estudo, em seu tipo ou forma, os tutores e docentes ou ainda aos próprios discentes. Para 
esse autor, seguindo uma ordem de importância para os componentes que devem ser privilegiados, visando ao bom desenvolvimento de qualquer tipo de formação, mas, neste caso, em especial para a modalidade de educação a distância, o aluno deve ser visto como elemento central e para ele devem estar voltadas todas as ações na educação, em qualquer modalidade.

Em EaD, essas ações devem estar sempre muito explícitas, sempre bem comunicadas; e os tutores, ou qualquer elemento que faça esse papel, devem estar sempre disponíveis para não causar nenhum mal-entendido ou embaraço na comunicação, em particular se o estudante não tem experiência na área.

Objetivando a permanência de cursistas em EaD, David Kember (1995), Diane Billings (1988) e Vincent Tinto (1975) (MOORE; KEARSLEY, 2007) desenvolveram modelos formais para conclusão de curso em que consideram a interação dos estudantes com professores, tutores, colegas e qualquer outro ator envolvido como um dos fatores determinantes não só da permanência, mas do sucesso dos cursistas. A preocupação dos pesquisadores da área mostra a importância dessa relação.

\section{b) Fatores relacionados à manutenção dos alunos (cursistas)}

Para melhor compreender as relações entre cursistas e tutores nas disciplinas analisadas, traçamos um breve perfil dos tutores que atuaram ao longo dos períodos estudados aqui. Os tutores serão identificados por letras; são 10 indivíduos. Consideramos algumas características tidas como relevantes em editais e concursos realizados para tutores na modalidade de educação a distância e por pesquisadores da área (GUTIERREZ; PRIETO, 1994; MACHADO, 2003; MALVESTITI, 2005; NOBRE, 2005) que poderíamos comprovar apenas analisando o Curriculum vitae de cada tutor. Na segunda coluna do Quadro 2, os tutores estão identificados pelas suas respectivas formações acadêmicas, segundo o mais alto título obtido.

Ainda no Quadro 2, foi considerado se o tutor (i) era especialista na área da disciplina em que atuaria; (ii) se estava inserido em alguma instituição de pesquisa ou ensino de nível superior como pesquisador e/ou aluno de pós-graduação; e (iii) se já possuía experiência em EaD.

Quadro 2: Titulação acadêmica e características dos tutores atuantes nas disciplinas analisadas neste trabalho. Fundação Cecierj - Diretoria de Extensão, 2011

\begin{tabular}{|c|c|c|c|c|}
\hline Tutor & Título acadêmico & $\begin{array}{l}\text { (i) Especialista na } \\
\text { área do curso }\end{array}$ & $\begin{array}{c}\text { (ii) Atuando em pesquisa } \\
\text { acadêmica }\end{array}$ & $\begin{array}{l}\text { (iii) Experiência } \\
\text { em EaD }\end{array}$ \\
\hline A & $\begin{array}{c}\text { Mestre em processo de } \\
\text { doutoramento }\end{array}$ & SIM & SIM & SIM \\
\hline B & $\begin{array}{c}\text { Mestre em processo de } \\
\text { doutoramento }\end{array}$ & NÃO & SIM & SIM \\
\hline $\mathrm{C}$ & Mestre & NÃO & SIM & NÃO \\
\hline $\mathrm{D}$ & $\begin{array}{c}\text { Mestre em processo de } \\
\text { doutoramento }\end{array}$ & NÃO & SIM & SIM \\
\hline$E$ & Mestre & NÃO & NÃO & SIM \\
\hline $\mathrm{F}$ & Mestre & NÃO & $\mathrm{NA} O$ & NÃO \\
\hline $\mathrm{G}$ & Mestre & NÃO & NÃO & NÃO \\
\hline $\mathrm{H}$ & Especialista & NÃO & NÃO & SIM \\
\hline I & $\begin{array}{c}\text { Mestre em processo de } \\
\text { doutoramento }\end{array}$ & SIM & SIM & SIM \\
\hline $\mathrm{J}$ & Especialista & NÃO & SIM & SIM \\
\hline
\end{tabular}


Ou seja, dentre os 10 tutores que participaram das 16 edições das disciplinas analisadas, oito já possuíam o título de mestre; dentre eles, quatro estavam em processo de doutoramento nas suas universidades e dois eram especialistas, na época (Quadro 2).

O Quadro 2 identifica a presença das características desejadas por tutor, além de sua formação acadêmica. Percebemos, então, a presença das três características - (i) Especialista na área do curso; (ii) Atuando em pesquisa acadêmica; e (iii) Experiência em EaD - nos tutores A e I e a ausência de todas elas nos tutores $\mathrm{F}$ e $\mathrm{G}$. Os tutores $\mathrm{B}, \mathrm{D}$ e J apresentam duas das três características e $\mathrm{C}, \mathrm{E}$ e $\mathrm{H}$, apenas uma delas.

\section{c) Análise das relações entre cursistas e tutores}

Tendo esclarecido o tipo de estrutura das disciplinas e os perfis dos estudantes e dos tutores traçados, passamos a verificar os resultados e as relações encontradas nas edições que foram analisadas. Foram alvo das análises realizadas daqui por diante cinco edições da disciplina NC ocorridas entre 2005 e 2007 e duas edições de disciplina CP ocorridas em 2009 e 2010, chegando a um total de 782 cursistas atendidos, após a evasão de início de curso (abandono).

Na Figura 4 podemos observar o número total de cursistas (alunos) designados por tutor no início do curso (barras claras); nas barras mais escuras está o número de cursistas que realmente iniciaram as atividades das respectivas disciplinas e foram atendidos por cada tutor após a evasão de início de curso.

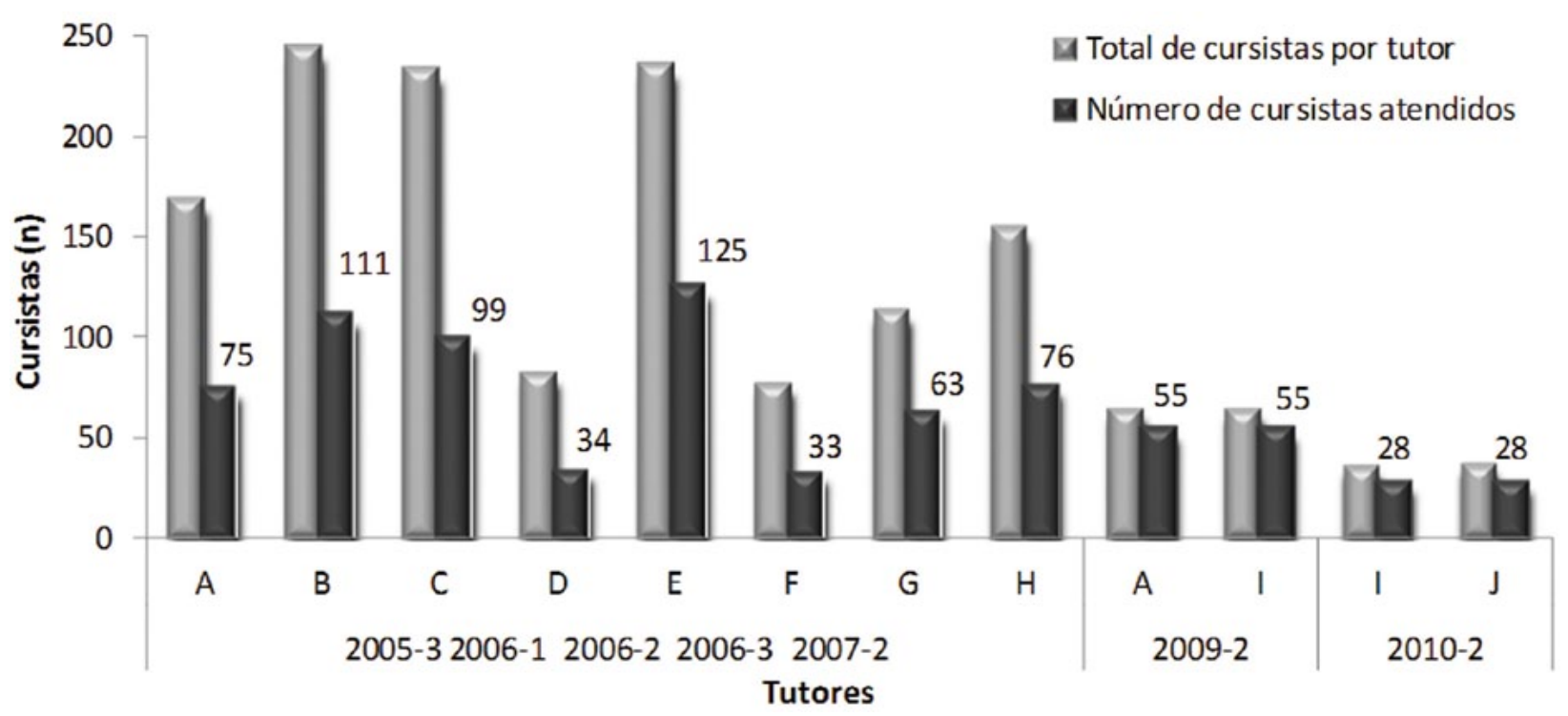

Figura 4: Número total de cursistas atendidos por tutor ao longo do período 2005 a 2007 e nos períodos de 2009 e 2010. Fundação Cecierj - Diretoria de Extensão, 2011.

Como vemos, o número de cursistas atendidos varia bastante em cada caso. Nas edições de 2009-2 e 2010-2 havia dois tutores dividindo a turma (Figura 4). Segundo García Aretio (1994), a desenvoltura de comunicação de cada tutor influencia no sucesso dessa parceria e o menor número de cursistas atendidos supostamente facilita o processo de comunicação.

A seguir investigamos o número de interações realizadas entre cursistas e tutores, lembrando que a cada atividade realizada os tutores deveriam corrigir a resposta do cursista e poderiam retornar um comentário ao menos e que a esse comentário poderia caber uma ou mais réplicas do cursista.

Contando o total de comentários realizado por tutor, chegamos à média de comentários dos tutores por cursista expressa na Figura 5. 


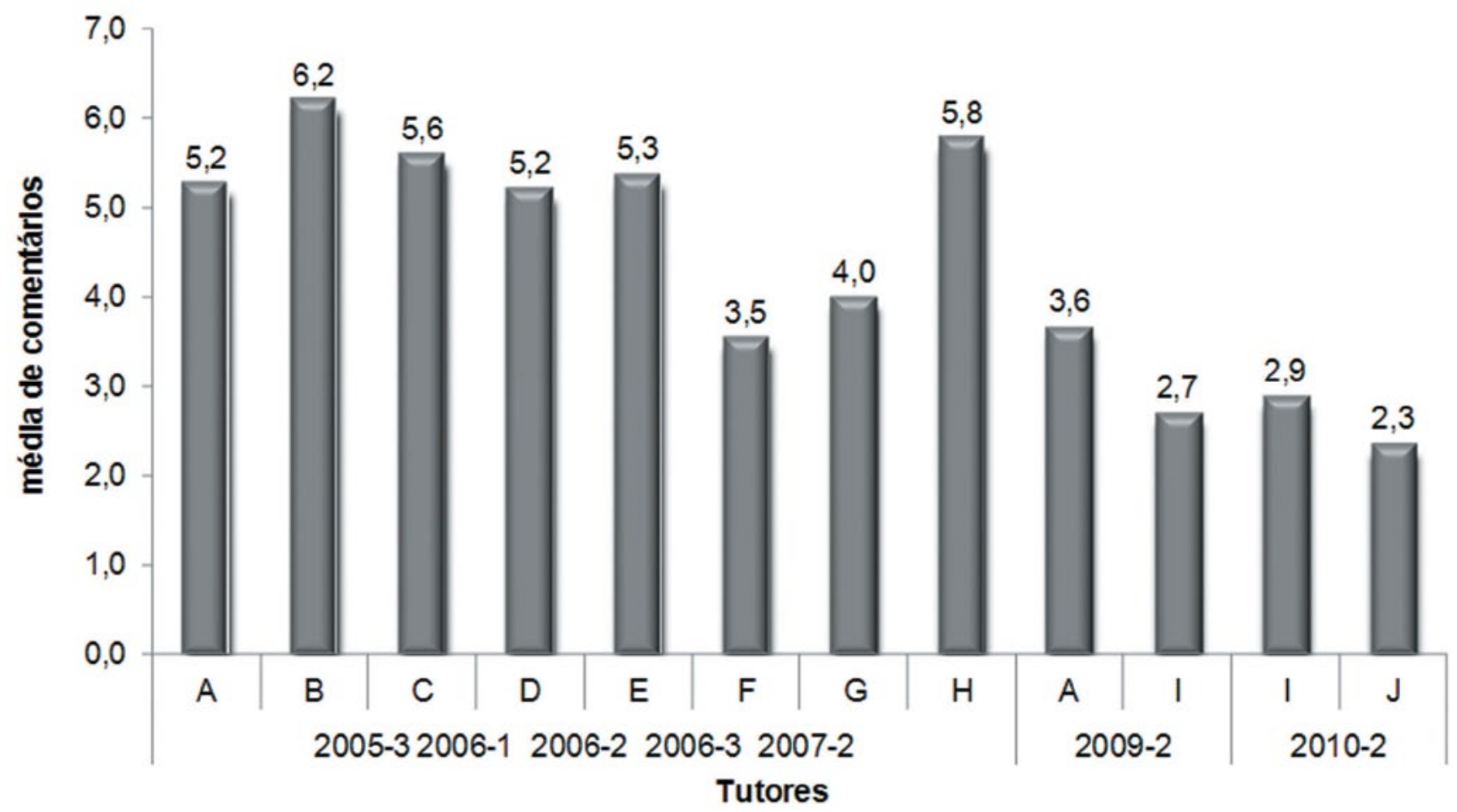

Figura 5: Número médio de comentários (retornos) dos tutores para cada cursista nas disciplinas com edições entre 2005 e 2007 e na disciplina com edições em 2009 e 2010. Fundação Cecierj - Diretoria de Extensão, 2011.

Vale lembrar que são disciplinas diferentes; considerando o número mínimo de comentários para as edições de 2005 a 2007 como quatro e para as edições de 2009 e 2010 como dois e meio $(2,5)$, de acordo com o número de atividades e pelo tipo de interação exigida, percebemos que o tutor $G$ realizou o mínimo de comentários e o tutor $F$ teve um número médio de comentários por cursista abaixo da média esperada para essa disciplina (Figura 5).

Os tutores $\mathrm{B}, \mathrm{C}$ e $\mathrm{H}$ apresentaram as maiores médias de interação. Não necessariamente interações que evoluíram para um diálogo, na concepção de Moore. Segundo esse autor, "o diálogo, em uma relação educacional, é direcionado para o aperfeiçoamento da compreensão por parte do aluno" (MOORE, 2002).

Podemos identificar que alguns tutores (nomeadamente, A, B, C, D, E, H e I) realizaram mais interações que o mínimo obrigatório para que os cursistas obtivessem retorno sobre suas respostas ou comentários. O número excessivo de retornos pode configurar alguma dificuldade na compreensão de determinada atividade/discussão ou pode indicar o aprofundamento na discussão/correção iniciada. Ou seja, uma média de retornos do tutor maior que o mínimo esperado pode ser um fator positivo para o desenvolvimento do processo de aprendizagem. O mais importante aqui é motivar o maior número possível de cursistas a participar das discussões, realizando ao menos um retorno.

Identificamos ainda (dados não mostrados em figuras ou tabelas) que os tutores $\mathrm{G}$ e $\mathrm{H}$ mantiveram comunicação ativa com menos de $20 \%$ e cerca de $10 \%$ dos cursistas, respectivamente. Ou seja, o tutor $\mathrm{H}$, por exemplo, teve uma média alta de comentários (5,8 na Figura 5), embora tenha sido com um baixo número de cursistas.

Na mesma amostra, verificamos a porcentagem de desistentes e quantos cursistas encerraram as disciplinas, valores expressos na Figura 6. Dentre os que encerraram, verificamos quantos obtiveram sucesso ao final, tendo sido aprovados (Figura 7). 


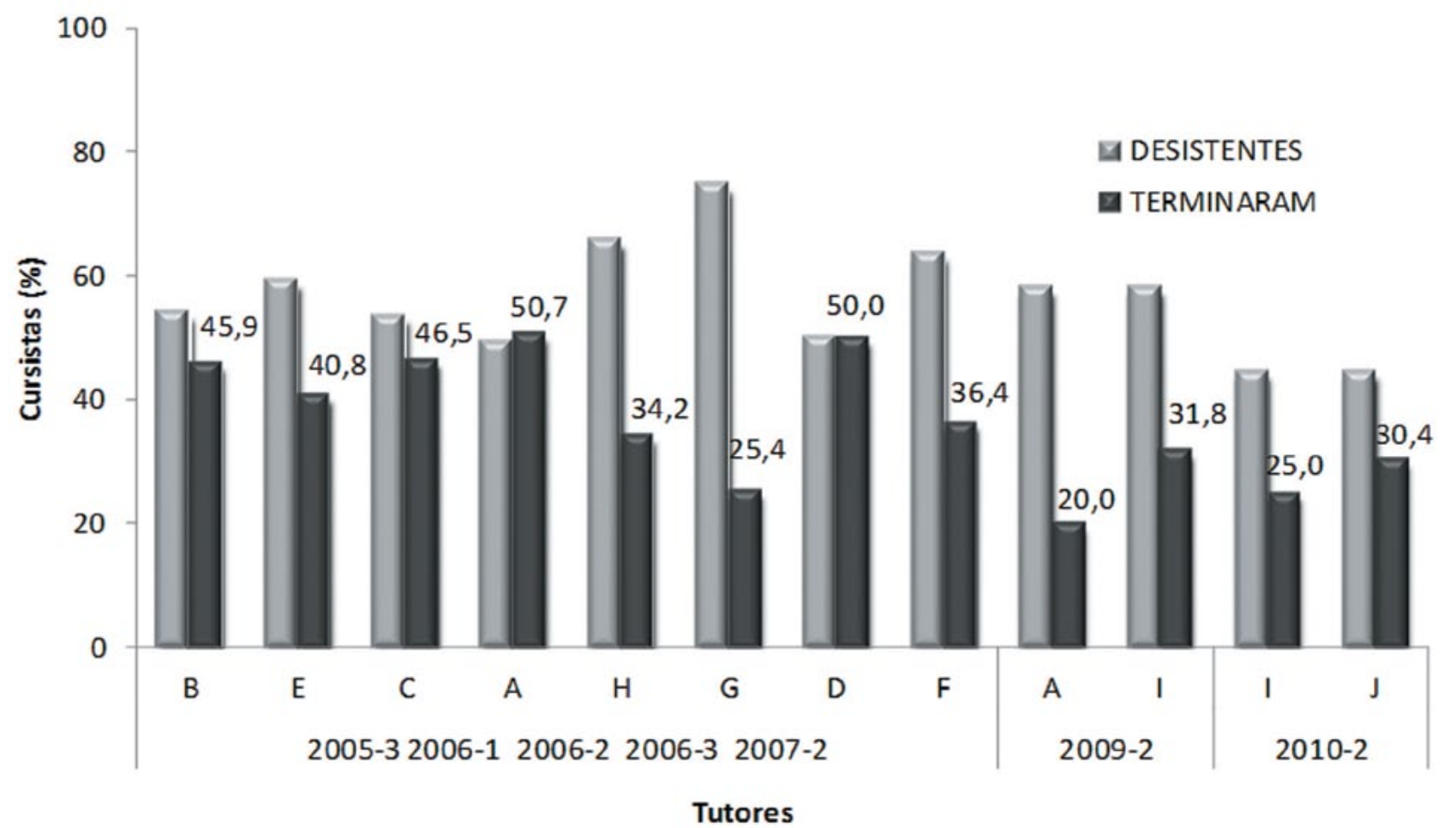

Figura 6: Total de cursistas atendidos por cada tutor ao longo do período 2005 a 2007 e nos períodos 2009 e 2010, evidenciando os desistentes e os que finalizaram (terminaram) a disciplina. Fundação Cecierj - Diretoria de Extensão, 2011.

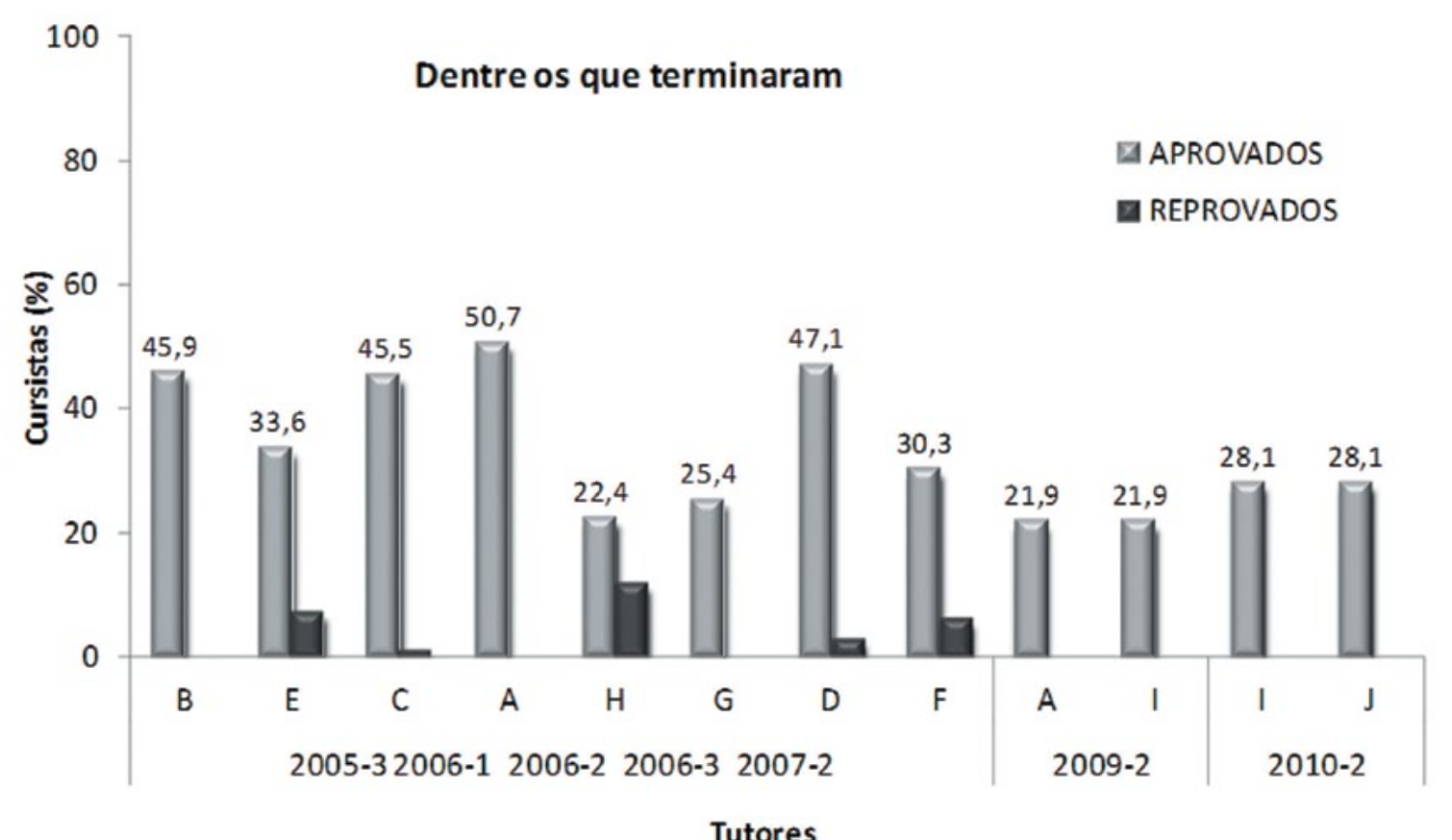

Figura 7: Detalhando, dentre os cursistas que finalizaram (terminaram), os aprovados e os reprovados, nas mesmas disciplinas analisadas entre os anos de 2005 a 2007 e em 2009 e 2010. Fundação Cecierj - Diretoria de Extensão, 2011. 
Não podemos atribuir totalmente o sucesso (ou não) obtido ao final das disciplinas - que, conforme Ostman e Wagner (1987) e Nash (2005), é multifatorial - às relações estabelecidas entre cursistas e tutores, mas esse é um dos fatores principais, tendo em vista que, numa perspectiva dialógica, é essa relação que irá complementar as discussões, fomentar e facilitar o aprendizado do aluno, esclarecendo dúvidas e possíveis dificuldades que forem surgindo no decorrer do curso (MOORE, 2002).

Nesse caso, analisando a soma dos indicativos até aqui, percebemos alguns pontos que podem ser associados. Devemos destacar que mais de $40 \%$ dos cursistas que compunham os grupos dos tutores $\mathrm{A}, \mathrm{B}$, $\mathrm{C}$, I e J encerraram o curso com sucesso, ou seja, não houve reprovação (Figuras 6 e 7). Os demais, menos de $60 \%$, compõem o grupo de evadidos, aqui denominados desistentes por não terem realizado as avaliações.

O tutor D - que não era especialista no tema da disciplina, mas realizava atividades de pesquisa acadêmica e tinha experiência na modalidade $\mathrm{EaD}$ - também apresentou índice de comunicação com os alunos dos mais altos e porcentagem das maiores nesse grupo de alunos, encerrando com sucesso a disciplina $50 \%$ de cursistas (Figura 6), com a ressalva de que, nesse grupo, um dos cursistas não obteve sucesso ao final (Figura 7). No entanto, devemos considerar que esse evento pode não ter nenhuma relação com a atuação do tutor. Outras variáveis, inclusive relacionadas diretamente ao cursista, precisariam ser analisadas.

Os tutores A e I apresentavam as características que, baseadas na literatura, tomamos como relevantes para tutores em $\mathrm{EaD}$ : ser especialista na área em que atua, desenvolver pesquisa na academia e possuir experiência prévia em EaD (Quadro 4). Não foi possível verificar o número de retornos de $\mathrm{I}$, em função de os dados não estarem completos, mas o tutor $\mathrm{A}$ se comunicou, ao menos uma vez, com todos os cursistas e retornou mais de uma vez as respostas de mais de $25 \%$ de seus alunos. Percebemos isso facilmente comparando o número de comentários (retornos) efetuados por A nas disciplinas com edições entre 2005 e 2007 (Figura 5).
Os tutores $\mathrm{B}$ e $\mathrm{C}$, cujos currículos indicavam atuação em pesquisa acadêmica na época, embora não tivessem experiência em $\mathrm{EaD}$, eram muito ativos nos fóruns, com números de retorno dentre os mais altos. O tutor $\mathrm{J}$ também possuía atividade de pesquisa acadêmica e boa comunicação nos fóruns, somadas à experiência anterior em $\mathrm{EaD}$. Nenhum dos três últimos tutores citados era especialista no tema do curso (Quadro 4).

Até aqui os tutores apresentavam pelo menos duas das três características consideradas relevantes para o perfil do tutor em $\mathrm{EaD}$, comunicabilidade com os cursistas acima da média do grupo e maior número de cursistas com ao menos um contato.

Os tutores E e H possuíam experiência anterior em $\mathrm{EaD}$, mas não eram especialistas na área dos cursos e não atuavam em pesquisa acadêmica, ou seja, careciam de duas das três características consideradas relevantes em editais e concursos realizados para tutores na modalidade de educação a distância e por pesquisadores da área (GUTIERREZ; PRIETO, 1994; MACHADO, 2003; MALVESTITI, 2005; NOBRE, 2005), mas quantitativamente se comunicavam acima do mínimo esperado. Ambos apresentaram um número médio de comentários por aluno maior que o mínimo exigido, embora o tutor $\mathrm{H}$ tenha se comunicado com um número pequeno de cursistas.

Os tutores $\mathrm{F}$ e $\mathrm{G}$ não apresentavam nenhuma das características que tomamos como relevantes para tutores em $\mathrm{EaD}$ (ser especialista na área em que atua, estar desenvolvendo pesquisa na academia e ter experiência prévia em EaD). Além disso, apresentaram um número de comentários abaixo do mínimo esperado nas disciplinas avaliadas.

Os tutores $\mathrm{E}, \mathrm{F}, \mathrm{G}$ e $\mathrm{H}$ finalizaram os cursos com $40 \%$ ou menos dos cursistas e três deles apresentavam reprovados em seus grupos, numa porcentagem que alcançou, no máximo, cerca de $12 \%$ do total de alunos que chegou à final. Dentre esses quatro, o tutor que não teve reprovação em seu grupo $-G$ - foi o que terminou a disciplina com o menor número de cursistas $-25,4 \%$, com $74,6 \%$ de desistentes - embora apresentasse o terceiro menor número na relação 
tutor-cursista. Ou seja, foi o grupo em que foi observado o maior índice de desistência ao longo da disciplina (Figuras 6 e 7) e a menor relação tutor-cursista ao final.

Como o tipo de comentário realizado pelos tutores (discurso) não foi investigado, por não ser parte do nosso objeto de estudo, nada podemos inferir sobre a qualidade do diálogo realizado.

O resultado sugere que as características observadas provavelmente influenciaram de alguma forma as relações entre tutores e cursistas nas disciplinas em questão. Observando os dados apresentados até aqui, percebemos que os tutores $\mathrm{A}, \mathrm{B}$, $\mathrm{C}, \mathrm{D}$, I e J obtiveram os melhores resultados finais em termos de número de cursistas obtendo sucesso ao final do curso e menor número de desistentes. Eles apresentavam o maior número das características relevantes - com exceção de $\mathrm{C}$, que apresentava apenas uma, mas fez uma das melhores médias de comunicação e retorno aos cursistas, mantendo $46,5 \%$ de cursistas até o final da disciplina contra $53,5 \%$ de desistentes, embora tivesse o terceiro maior número de cursistas por tutor.

De alguma forma entendemos que os critérios descritos na literatura e a frequência e amplitude do discurso na interação são características importantes para tutores a distância em EaD. Nossa experiência dá uma pequena amostra da importância dessas competências para a atuação dos tutores. Novos e mais complexos estudos devem ser desenvolvidos a partir dos resultados encontrados neste trabalho e esperamos ter confirmado o valor dos critérios propostos por vários autores e a relevância da presença constante do tutor, mantendo uma dialogicidade permanente.

\section{Considerações finais}

Em nenhum momento neste breve estudo pretendemos destacar as relações tutor/cursistas em EaD como mais importantes ou relevantes para a manutenção ou sucesso dos participantes. Esse tipo de relação é apenas um dos fatores, num leque enorme de variáveis que leva ao sucesso nessa modalidade de ensino.

Esperamos, na verdade, poder contribuir para a elucidação de alguns pontos na discussão sobre as características relevantes de tutores em EaD. Sabemos o quanto se espera de um tutor e como é fundamental sua atuação, mas consideramos excessiva a expectativa que se coloca nesse parceiro. Alguns autores chegam a listar dezenas de quesitos. Em seu artigo, Pires e Accorsi (2012) assumem a importância de uma atividade acadêmica constante para os tutores e admitem que "o papel do tutor inicialmente estabelecido não é capaz de dar conta das necessidades existentes no âmbito da educação a distância".

As características essenciais de um tutor devem trazer segurança e tranquilidade para que ele possa atuar com flexibilidade, mostrando capacidade de adaptação a novas situações inusitadas que venham surgir ao longo do período de curso, sem dar a perceber inexperiência ou insegurança ao cursista que, por estar distante, precisa confiar muito naquela relação $e$ desejar mantê-la.

Nossos dados mostraram que tutores especialistas em suas áreas, com experiência em EaD e com atividade acadêmica constante - mesmo atendendo um número, em alguns casos, quatro vezes maior que seus colegas que não apresentavam essa característica - apresentaram turmas com evasão significativamente menor e sem reprovação, para este grupo.

\section{Referências}

ALMEIDA, I. C.; ILDETE, M. Educação a distância: um estudo dos motivos de desistência de um curso a distância via internet. Maio/2008. Disponível em http:/www.abed.org.br/congresso2008/ tc/552008112738PM.pdf. Acesso em jul/2011.

ALMEIDA, O. C. S. Evasão em cursos a distância: análise dos motivos de desistência. Maio/2008. Disponível em http://www.abed.org.br/congresso2008/tc/552008112738PM.pdf. Acesso em jul/2011. 
ALMEIDA, O. C. S. Investigando os fatores influenciadores da desistência de cursos a distância. Maio/2010. Disponível em http://www.abed.org.br/congresso2010/cd/252010162044.pdf. Acesso em jul/2011.

BARBOSA, M. F. S. O.; REZENDE, F. A prática dos tutores em um programa de formação pedagógica a distância: avanços e desafios. Interface (Botucatu), 10 (20). 2006. Disponível em http://www.scielo.br/scielo. php?script=sci_arttext\&pid=S1414-32832006000200014\&lng=en\&nrm =iso $>$. Acesso em $\mathrm{mar} / 2012$.

BIAZUS, C. A. Sistema de fatores que influenciam o aluno a evadir-se dos cursos de graduação na UFSM e na UFSC: um estudo no curso de Ciências Contábeis. Florianópolis, SC. Tese (doutorado). Universidade Federal de Santa Catarina, Centro Tecnológico. Programa de Pós-graduação em Engenharia de Produção. 2004.

BRASIL, MEC/INEP. Censo da Educação Superior. 2011. Disponível em http://sistemascensosuperior.inep. gov.br/censosuperior_2011/. Acesso em maio/2012.

BURKE, P. J.; CHRISTENSEN, J. C.; FESSLER, R.; McDONNELL, J. H.; PRICE, J. R. The teacher career cycle. Model development and research report. In: Annual Meeting of the American Educational Research Association, Washington - DC. (comunicação apresentada). 1987.

CAVACO, M. H. Ofício do professor: o tempo e as mudanças. In NÓVOA, A. (ed.). Profissão Professor. Porto: Porto Editora, 1991. p.155-191.

CAVACO, M. H. Ser professor em Portugal. Lisboa: Teorema. 1993.

Censo EAD.BR. Relatório analítico da aprendizagem a distância no Brasil. Organização: Associação Brasileira de Educação a Distância. São Paulo: Pearson Education do Brasil, 2010.

COGAN, S. Activity-Based Costing - ABC. $2^{a}$ ed. São Paulo: Pioneira, 1995.

Fundação CECIERJ - Diretoria de Extensão. Disponível em http://www.cecierj.edu.br/extensao/. Acesso em fev/2012.

GALERA, J. M. B. Missão brasileira sobre educação a distância na Inglaterra e Espanha. Brasília: CONSED, (Relatório Técnico CONSED), 1998.

GARCIA ARETIO, L. Educación a distancia hoy. Madrid: UNED, 1994.

GARRISON, D. R.; ANDERSON, T.; ARCHER, W. Critical inquiry in a text-based environment: computer conferencing in higher education original research article. The Internet and Higher Education, vol. 2, no 2-3, p. 87-105, Spring 1999.

GUTIERREZ, F; PRIETO, D. A mediação pedagógica: educação a distância alternativa. Campinas: Papirus. 1994.

HARASIM, L.; HILTZ, S. R.; TELES, L.; TUROFF, M. Learning networks: a field guide to teaching and learning online. Cambridge: MIT Press. 1995.

HUBERMAN, M. Teacher development and instructional mastery. In: HARGREAVES, A.; FULLAN, M. G. (eds). Understand Teacher Development. New York: Teachers College Press, 1992. p. 92-142.

HUBERMAN, M.; SCHAPIRA, A. Cycle de vie et enseignement. Le cycle de vie de l'enseignant secondaire. Les Sciences de l'Éducation, (3), p. 3-14, 1985. 
LISONI, J. A.; LOYOLLA, W. Custos: uma análise comparativa entre educação presencial e a distância. 2012. Disponível em http://www2.abed.org.br/visualizaDocumento.asp?Documento_ID=33. Acesso em jan/2012.

LÜDKE, Menga. Sobre a socialização profissional dos professores. Cadernos de Pesquisa, São Paulo, n. 99, p. 5-15, 1996.

MACHADO, L. D. O papel do tutor em ambientes online. 2003. Disponível em: http://www.abed.org.br/ nordeste/downlaad/liliana.pdf. Acesso em jul/2006.

MALVESTITI, M. L. Tutoria em cursos pela internet. 2005. Disponível em: http://www.abed.org.br/ congresso2005/por/pdf/032tcd5.pdf. Acesso em jul/2006.

MOORE, M. G. Theory of transactional distance. In: KEEGAN, D. (ed.). Theoretical principles of distance education. New York: Routledge, 1993. P. 22-38.

. Teoria da distância transacional. Revista Brasileira de Aprendizagem Aberta e a Distância. vol. 1. ago/2002. Original publicado em Keegan, D. Theoretical Principles of Distance Education. Trad. Wilson Azevêdo, com autorização do autor. Revisão de tradução: José Manuel da Silva. London: Routledge, 1993. p. 22-38. Disponível em: http://www.abed.org.br/revistacientifica/_brazilian/edicoes/2002/2002_Edicao. htm. Acesso em ago/2008.

MOORE, M.; KEARSLEY, G. EaD: uma visão integrada. São Paulo: Thomson Learning, 2007.

NASH, R. D. Course completion rates among distance learners: identifying possible methods to improve retention. University of West Georgia, Distance Education Center. Journal of Distance Learning Administration, 8(4), 2005. Disponível em: http://www.westga.edu/ distance/ojdla/winter84/nash84.htm. Acesso em jan/2012.

NOBRE, C. V. Dialogando com os vários atores envolvidos no processo de transição de tutoria presencial para tutoria a distância em programas de educação a distância. 2005. Disponível em: http://www.abed.org.br/congresso2005/por/pdf/127-tc-f5.pdf. Acesso em jul/2006.

NÓVOA, A. (org.). O passado e o presente dos professores. In: . Profissão professor. Porto: Porto, 1999. p. 7-34, apud BARBOSA, M. F. S. O.; REZENDE, F. A prática dos tutores em um programa de formação pedagógica a distância: avanços e desafios. Interface (Botucatu), 10 (20). 2006. Disponível em: http://www.scielo.br/ scielo.php?script=sci_arttext\&pid=S1414-32832006000200014\&lng=en\&nrm=iso. Acesso em mar/2012.

OSTMAN, R.; WAGNER, G. New Zealand management students' perceptions of communication technologies in correspondence education. Distance Education, 8(1), p. 47-63. 1987. Disponível em http://www.tandfonline. com/doi/pdf/10.1080/0158791870080104. Acesso em jan/2012.

PIRES, F. J.; ACCORSSI, A. Tutoria em educação a distância. 2012. Disponível em: http://www2.abed.org. br/visualizaDocumento.asp?Documento_ID=86. Acesso em jan/2012.

RAFAELI, S.; SUDWEEKS, F. Networked interactivity. Journal of Computer Mediated Communication, 2(4), 1997. Disponível em: http://jcmc.indiana.edu/vol2/issue4/rafaeli.sudweeks.html. Acesso em nov/2007.

RUMBLE, G.; OLIVEIRA, J. Vocational education at distance. International perspectives. London: Kogan, 1992. 
TRESMAN, S. Towards a strategy for improved student retention in programmes of open, distance education: a case study from the Open University, UK. International Review of Research in Open and Distance Learning, 3(1), abr/2002. Disponível em: http://www.irrodl.org/index.php/irrodl/article/view/75/145. Acesso em jan/2012.

VALENTE, J. A. A espiral da aprendizagem e as tecnologias da informação e comunicação: repensando conceitos. In: JOLY, M. C. (Ed.). Tecnologia no ensino: implicações para a aprendizagem. São Paulo: Casa do Psicólogo, p. 15-37, 2002. 